\title{
Mind the gap: identifying barriers to students engaging in creative practices in higher education
}

\author{
Lluís Solé and Laia Sole-Coromina \\ Universitat de Vic, Vic, Spain, and \\ Simon Ellis Poole \\ Faculty of Education and Children's Services, University of Chester, Chester, UK and
Department of Research, Storyhouse, Chester, UK \\ Faculty of Education and Children's Services, University of Chester, Chester, UK and
Department of Research, Storyhouse, Chester, UK
}

Received 9 March 2020

Revised 20 April 2020

21 May 2020

31 May 2020

Accepted 3 June 2020

\begin{abstract}
Purpose - Creativity is nowadays seen as a desirable goal in higher education. In artistic disciplines, creative processes are frequently employed to assess or evaluate different students' skills. The purpose of this study is to identify potential pitfalls for students involved in artistic practices in which being creative is essential.

Design/methodology/approach - Three focus groups involving Education Faculty members from different artistic disciplines allowed for the identification of several constraints when creativity was invoked. This initial study used a quantitative approach and took place in the "Universitat de Vic" (Catalonia, Spain).

Findings - Findings suggest a correlation with existing literature and simultaneously point at some nuances that require consideration: emerging aspects embedded in creative processes that may help decrease some limiting effects that being creative can generate.

Research limitations/implications - The main limitations of this research derive from the very nature of the methodological approach. Focus group has been the single used source. Other means of collecting data, such as the analysis of programs, could be used in the future.

Originality/value - This case study, while culturally specific, offers a useful insight into the potential of further work in non-artistic disciplines but crucially across disciplines. It has tremendous value for the development of intercultural understanding in the higher education sector, specifically in terms of assessment.
\end{abstract}

Keywords Creativity, Higher education, Barriers, Pedagogy, Art, Creative practices

Paper type Case study

\section{Introduction}

Being able to position creativity is crucial if it is to have a place within the andragogue's educational philosophy or practice. Even more so if the barriers and obstacles to teaching with and for creativity are to be lifted. It is the intention of this introduction, to discursively locate the term creativity within a Higher Education (HE) setting. It would be difficult to do this without considering the tensions that institutional education systems face, albeit in a brief manner. As such creativity necessarily should be considered in relation to innovation and tradition not as oppositional but as bearing out the tension between them. In order to delineate a working definition of creativity, this paper will draw upon a body of work by researchers of creativity and creative practices.

As art educators involved in teacher training, we have been running our courses in music education and visual arts education respectively for a few years. There is a shared understanding among faculty members of the need to promote students' access and

(C) Lluís Solé, Laia Sole-Coromina and Simon Ellis Poole. Published in Journal of Work-Applied Management. Published by Emerald Publishing Limited. This article is published under the Creative Commons Attribution (CC BY 4.0) licence. Anyone may reproduce, distribute, translate and create derivative works of this article (for both commercial and non-commercial purposes), subject to full attribution to the original publication and authors. The full terms of this licence may be seen at http:// creativecommons.org/licences/by/4.0/legalcode

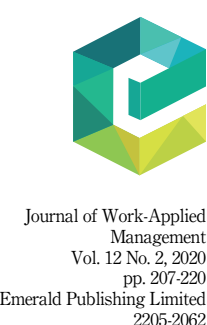

DOI 10.1108/JWAM-03-2020-0017 
JWAM

12,2

\section{8}

relationship with forms and formats of art, and the need to foster these aesthetic experiences with hands-on opportunities where students can explore artefacts and artworks, and through them. Underlying this, there is the understanding that art practices, whether appraisal or artmaking, provide "a way of knowing" (Eisner, 2012, p. 10) that is singular and yet transferable to other fields of knowledge.

As part of our conversations on learning outcomes and teaching-learning practices, the need to share and explore assessment criteria emerged, when art-related content or processes were involved within a formal study: this took the form of a case study of teachers' and students' perceptions on creative process assessments. And yet, the emphasis on assessment which would have led us to explore our students' paths, processes and meaning they ascribe to it (Huerta, 2019) found an unexpected barrier or obstacle (Dewey, 1934/2005) that modified the study's trajectory: the case study became concerned with creativity as a constraintprocess experience.

Regardless of the disciplinary boundaries, through the teaching of the philosophy or the methods of instruction of participating faculty members, we became concerned with creativity as experienced in an educational environment: what the perceptions of teachers and students engaged in creative processes were; in short, we became interested in how creative processes may unfold within a pedagogical event, and with the "local intensities as they form and develop in a learning encounter" (Atkinson, 2016, p. 2).

The following study attempts to understand the barriers and difficulties educators must overcome in the classroom if creativity is to thrive and give affordance for arts-based or artistic modalities of assessment. Two major aims were proposed:

(1) To identify perceptions of teachers about pitfalls and barriers, which may arise in HE, when students must develop learning activities in which creative thinking through artistic disciplines is required.

(2) To explore ways of minimising the potential reluctance of education students when engaging with creative practices.

\section{Creativity and art}

The context of creativity as a conceptual space that artistic practices could sit within will first be considered. Conceptualisations of creativity, where academics such as Dellas and Gaier (1970) "treated creativity as if it were an individual attribute" (Craft, 2005, p. 134) might form suitable understandings in their field. However, they could be seen as debatably detrimental to understandings of creativity, from the perspective of a creative practitioner or artistic educator. For example, such psychological perspectives of creativity have continued to influence research and society since Torrance's (1966) first psychometric tests. The idea that it could be a cognitive characteristic that produces "eminent creativity (also called "Big-C"), which is reserved for the great" (Kaufman and Beghetto, 2009, p. 1), arguably disregards social and political factors.

On the contrary, Bronner (2015), while considering the relationship between folklore and creativity notes how the psychologist Freud called for greater synthesis and collaboration between the fields of psychoanalysis and folklore. So in terms of locating a context of creativity within an educational sphere, the proposition that a major distinction be made between '"high' creativity, shown by the exceptional person, and 'ordinary' or 'democratic' creativity, which can be shown by everyone" (Craft, 2001) is a false dichotomy. A position that appreciates creativity encompassing but not entirely made up the tension between innovation and tradition (Poole, 2017), would be a useful one, given the traditions that exist within educational practices and the need to innovate them to respond to social and political change.

So while, educational psychologist Kaufman (2016) states of creativity that "we have agreed on a basic definition for more than 60 years" (p. 25), Runco, Jaeger and others would 
disagree given that their recent works have all been critically concerned with definitions of creativity (Cropley and Cropley, 2008; Runco and Jaeger, 2012). Kaufman (2016) also suggests "that creativity is an activity that produces something that is both new and task-appropriate" (p. 25). The National Advisory Committee on Creative and Cultural Education (NACCCE) concurred that it should be thought of as an: "imaginative activity fashioned so as to yield an outcome that is of value as well as original" (Robinson and Craft, 1999, p. 30). In these definitions, both new and original are key ideas, which sometimes are alternatively labelled as novel or novelty.

A definition of innovation might readily be aligned with these notions. They are themselves however ambiguous and misleading in many ways, within the context of education and now more so in the digital world, considering for example ideas of authenticity. As ideas, new and original also have a connection with globalism and capitalism, especially if used in conjunction with the other key ideas of task-appropriate, or value. The latter which is a label with quite clear connotations in research on economics and creativity; "it describes how original and valuable products and ideas depend on the current market, and more specifically on the cost and benefits of contrarianism. .." (Runco and Jaeger, 2012, p. 92).

Aware, but wishing to avoid accusations of a domain-specific perspective, an alternative substantiation of creativity's definition is offered from which, and for which, this study develops. Providing that is, that education is read as interchangeable with creativity, education is connected with culture, process, performance and construction in the strictest of anthropological senses. And regardless of whether there is a current trend in $\mathrm{HE}$ at present to engage with the discourse of creativity for whatever reason, there is nonetheless an urgent need to disentangle and disenchant creativity within education; to pierce the romantic façades and arrive at the deeper reasons for those constructions. The performance of creativity has long since drifted away from its original texture and context; the praise of the original and primary has become part of a secondary system intimately connected with advertising and public relations activities, with economic and political interests. If nothing else this study demonstrates that educators wish to rescue creativity and artistic practices from such systems and to reinstill them within a different educational sphere, but they are finding barriers and obstacles that prevent them for doing so.

So, in summary, there are clear connections between certain definitions of creativity and tradition and innovation. These are played out in educational systems, expressly, around notions of the individual and their entanglement with creativity and the social world. A working definition of creativity for this study would avoid the entirely psychological, personal, market- or outcome-driven understandings of what it is to innovate; creativity would not mean an acting individual, thought of as particularly creative, creating something new, original, or of value. Creativity would instead hold meanings that were social; meanings that were connected with the everyday happenings of people. It would also expand its meaning to have a different relationship with time; to embrace connotations beyond the new and original, such as renew, restore, alter or return to.

\section{Ways of knowing}

Some of the underlying assumptions regarding the ways of knowing creative processes are: (1) through the arts, we engage in a process of inquiry that allows us to make sense of changing and unpredictable phenomena in our world/environment; (2) the arts promote individual autonomy, in that they mobilise what is subjective, in opposition to objective knowledge; as Eisner (2012) states: "the arts are means of exploring our own interior landscape" (p. 11). What is at play when making sense of an aesthetic encounter is what one has experienced, lived or known; similarly, the arts (3) favour divergent thinking: multiple responses or ways to relate art materials and practices can meet a single question or problem; 
JWAM

12,2

(4) art practices foster critical thinking, by offering avenues to look at ourselves and our environment from diverse standpoints, and through materials and formats that present themselves as questions rather than responses; (5) aesthetic encounters appeal to our senses, mobilise effects and may lead to a more significant learning; and (6) exposure to art induces inspiration, which in turn facilitates performance on creative tasks (An and Youn, 2018).

\section{0}

Creativity in $H E$

There is consensus among the educational community on the importance of creativity as an essential skill for students in HE. Some of the reasons, as argued by Jackson (2006b) are: (1) being creative is a fundamentally human characteristic, (2) creativity is integral for any discipline field of endeavour and (3) creativity is necessary in order to survive in a complex, ever-changing unpredictable world. And yet, there are diverse ways in which to approach creativity, as well as different meanings and nuances about what being creative means.

The ambiguity of the concept seems doubtless and has a strong contextual meaning: being creative means different things in different contexts and cultures (McGoldrick, 2002; Oliver, 2002). As Boden (2005, p. 75) mentions "people of a scientific cast of mind, generally define creativity in terms of novel combinations of old ideas," while within the music field, creativity can be related with the concept of flow (Csikszentmihalyi, 2009), as suggested by MacDonald et al. (2006).

At the same time, creativity can be approached as a skill, as a process or as the mutual interaction of skill and process with an environment or a given situation. It could be considered too, as stated in the call for papers for this journal issue, democratically and collaboratively: a "space of extraordinary openness, a place of critical exchange" from where to imagine and act upon our realities (Soja, 1996, p. 5). This article focuses on creativity as perceived and experienced by teachers within their practice in the context of $\mathrm{HE}$. Time-based aspects, such as the sense of duration of an experience, as well as the variations and the sense of "unity" that pervades the course of an experience to its fulfilment (Dewey, 1934/2005, p. 36), are considered too.

Coming to terms with the meaning of creativity, Jahnke et al. (2017) developed a study within the culture of $\mathrm{HE}$, which identified six clustered facets of teachers' conceptions on students' creativity. Being creative was expressed as:

(1) Self-reflective learning;

(2) Independent learning (organising decisions for learning autonomously);

(3) Showing curiosity and motivation;

(4) Producing something;

(5) Showing multi-perspective;

(6) Reaching for original, entirely new ideas.

While this may offer a valuable indicator of behaviours and practices in actions where creativity is involved, there is too, the variability within which these practices and behaviours are lived and perceived; i.e. the "single quality that pervades" an "experience in spite of the variation of its constituent parts" (Dewey, 1934/2005, p. 38).

According to Kleiman (2008), there are different approaches or conceptions about the way academics experience creativity in learning and teaching processes. Creativity can be perceived as (1) a constraint-focused experience, (2) a process-focused experience, (3) a product-focused experience, (4) a transformation-focused experience and (5) a fulfilmentfocused experience. While all these perceptions seem to acknowledge the relational nature of the experience, they distil diverse and even opposed qualities of how the process of mutual 
adaptation (Dewey, 1934/2005, p. 45) manifests. In more tangible terms, for example, creativity could be perceived for some teachers as a barrier, obstacle or difficulty, which constrains the flow of actions and thoughts. Likewise, some students may be reluctant to express themselves creatively. In short, mind the gap with creativity.

\section{Barriers to creativity}

It would seem, therefore, that all that glitters is not gold. Is creativity a wolf in sheep's clothing?

Some barriers or difficulties can appear when students are compelled to bring their creativity into play. Jackson (2006a) argues that the main problem with creativity in HE is the lack or absence of creativity in assessment criteria for most courses. Indeed, creativity is rarely an explicit goal of learning and assessment processes. Jackson (2006a) encourages coursedesigners to provide more opportunities for students to be creative through leading education in a paradigm shift where students and teacher's creativity is valued, encouraged and recognised. In general terms, and with a contextual meaning, we are clearly facing a situation in which creativity is being progressively incorporated in $\mathrm{HE}$ programmes as a desirable goal or ability to be enhanced.

Nevertheless, creativity could be deemed as a limiting condition or weakness for certain individuals in certain contexts. Several studies have focused on barriers to creativity in $\mathrm{HE}$ from different contexts (Alencar, 2001; Alencar et al., 2003; Kazerounian and Foley, 2007; Hilala et al., 2013; Morais et al., 2014a, b). In Engineering education, the biggest barrier for creativity according to Kazerounian and Foley (2007), for instance, is how creativity is poorly valued in opposition to the accuracy of processes involved in design. However, in Physical Education and Sport Sciences, one of the main inhibitors of creativity fostering classroom environment is the educational environment and resources and specifically the problematic translation of policy into practice, as suggested by Konstantinodou et al. (2015, p. 28).

From an individual-focused perspective, Alencar (1999) developed the Inventory of Barriers to Personal Creativity. According to this validated instrument, limiting factors to creativity can be grouped into four categories: difficulties related to inhibition or shyness (e.g. “. . I'm not prepared to express what I think"); time, opportunities and resources (e.g. “. . if there was more time to put my ideas into practice”); obstacles of a social nature (e.g. ". . . if I had not been limited by my family"); and the absence of or low personal motivation (e.g. “. . . if I had more energy").

This article presents and discusses some barriers to creativity in $\mathrm{HE}$ as found in a study with teachers. It also suggests possible avenues to reduce the impact of these barriers through the notion of accessibility in $\mathrm{HE}$ based on the principles of Universal Instructional Design (Silver et al., 1998). These principles have led universities to apply accessibility measures consisting of identifying learning barriers in order to mitigate their effect.

\footnotetext{
Methodology

This pilot study is contextualised within a case study bound to the context of an $\mathrm{HE}$ institution: the Education Faculty of Universitat de Vic in Catalonia, Spain. The study aims to understand and identify aspects and patterns of creative processes, which may allow building a system that integrates assessment criteria for faculty members. There is an emphasis on uniqueness and simultaneously the implicit understanding of its difference from other cases (Stake, 1995, p. 8). Case studies can be considered a "bounded system" (Creswell, 2007 , p. 73) in that they look at a diversity of sources, such as people and programmes, to gain a deep understanding of a phenomenon.

As mentioned above, the present case study focuses on faculty members teaching art-related courses, and the further case studies will broaden the scope, incorporating
} 
JWAM

12,2

perceptions from faculty members from diverse fields of knowledge, and education students about their perceptions of assessment when it comes to creativity. This article hence focuses on assessment criteria in art education-content courses through a series of focus groups with faculty members teaching art-related courses.

As a method of data collection, focus groups provide an efficient manner to collect participants' perceptions while allowing them the possibility to build upon others' perceptions. It has been described as an excellent data collection method to gain a deeper understanding of meanings, beliefs and cultures that influence feelings, attitudes and behaviours of individuals (Rabiee, 2004) as they allow the opportunity to discuss participants' perceptions, ideas, opinions and thoughts (Krueger, 2014).

This case study was designed as a series of three focus groups that were set up as an open conversation where participants could share practices and perceptions of assessing students' creative processes. The first focus group was designed to identify emergent themes and concerns from participants. These were then used to elaborate a semi-structured focus group protocol for the second and third sessions. In line with Krueger's recommendations (2014), participants of the first focus group were divided subsequently into two small focus groups, at which every concept or factor was discussed together. Conversations unfolded after the presentation of the study's aims, and the individual consent forms were gathered. These conversations were recorded, then transcribed and shared with all participants. Transcripts were analysed, coded by two participant-researchers and their analysis results were then cross-referenced to validate emergent themes and categories. Group of the first phase.

The three focus groups allowed the collection and analysis of data on assessment criteria in art education-content, and the identification of creativity as a constraint-experience, as an emergent and unexpected theme. This article focuses on creativity as a constraint-experience, and it presents some possible solutions in order to minimise perceived barriers or obstacles that emerge when creativity is elicited.

\section{Participants}

Participants in the first phase of the study are members of the Arts and Science Didactics department in the Education Faculty at Vic University (Spain). The group consists of 13 lecturers that are running art-related courses: four of them are involved in the discipline of visual arts education, four in drama education, two in music education, one in poetry and one in information technologies and communication (ITCs). Participants are senior and experienced faculty members involved in primary education, early childhood education, social education, design, engineering and sports degrees.

\section{Format}

Following the recommendations and guidelines suggested by Krueger (2014) the study's design proceeds through three focus group sessions, one building upon each other. Each focus group lasted one hour and a half and took place in a co-working comfortable room, and no more than eight participants were asked at once. Some days before each session, participants were notified through email reminding them of the session and informing them about the main topics which would be under discussion. In the first sessions, following suggestions made by Onwuegbuzie et al. (2009), explanatory framing texts were presented as stimulus material.

\section{Limitations}

The main limitations of this research derive from the very nature of the methodological approach. Focus group has been the single used source. Other means of collecting data, such 
as the analysis of programmes, could be used in the future. The second and third phases of this pilot study broaden the scope of the study, exploring students and teachers perspectives from non-art disciplines. For these phases, other instruments of data collection, such as questionnaires will provide new perspectives and approaches.

\section{Analysis}

Researchers have opted for a thematic analysis (Braun and Clarke, 2006) because it offers a

flexible approach and simple procedures, both useful for an exploratory study. The tapebased format has been used "because the researcher can focus on the research question and only transcribe the portions that assist in better understanding of the phenomenon of interest" (Onwuegbuzie et al., 2009, p. 4). An emergent-systematic focus group has been designed, "wherein the term emergent refers to the focus groups that are used for exploratory purposes and systematic refers to the focus groups that are used for verification purposes" (p. 6). Indeed, the first focus group was designed as an exploratory session in which participants were encouraged to actively participate with opinions, beliefs, perceptions, thoughts, ideas and feelings.

In the analysis process, concepts or words have been labelled, and then considered according to frequency, contextual meaning and degree of consensus. The transcriptions of the sessions were also used as support for the analysis. Two of the researchers reviewed the recordings and transcriptions. Terms and concepts related to, or identified as barriers to creativity were highlighted and clustered in different domains or categories. Atlas-ti was used for labelling terms and ascertaining the frequency of words. Only the terms/aspects that appeared in each reviewers' analysis were deemed to be significant factors to be considered. In the second focus group, every concept or factor was discussed together in a meeting.

\section{Findings}

The data gathered and analysed in the study suggests that while the artistic experience is perceived by the majority of educators as a powerful tool to elicit students' individual growth along the learning process in $\mathrm{HE}$, it comes with a set of difficulties or barriers. In an attempt to identify determining factors of assessing creative processes, researchers organised some of the emerging factors as found in the first focus group into three categories or stages: (1) preliminaries to elicit creative process within a class, (2) aspects related to the development of creativity within the teaching-learning process and (3) evaluation or reflexive factors once the creative process has ceased. While this organisation allowed for some clarity upon which to build the successive focus groups, it also helped to reveal the endurance of intersecting individual limitations that needed to be considered. The study identified four intersecting individual limitations perceived as obstacles to student's creativity within an educational setting: (1) individual reluctance or emotional block to be creative, (2) the need to be accompanied or to be guided and mentored by the teacher throughout a creative process, (3) time investment and time management of a creative process and (4) individual background. At the same time, the identification of these four dimensions seemed to show patterns of mutual interaction and dependencies.

\section{Individual reluctance or emotional block to being creative}

There was complete agreement that the obligation to be creative in HE can block and become immobilising for many individuals, especially in those grades or studies that are not specifically linked to the arts. In the same manner, risk and uncertainty, in a consensual way, were considered as desirable conditions from the educator's perspectives. And at the same time, participants agreed about the discomfort and feeling of awkwardness that this 
JWAM

12,2

uncertainty and risk assumption can generate for some students when grades are involved. Alongside this feeling of bewilderment, it seems to be important for students to acquire an understanding of the general meaning of the process, otherwise, emotional blocks could appear.

\section{Accompaniment / guiding}

The word accompaniment was the third in the ranking of the frequency of tagged concepts in the focus groups. A thorough analysis reveals the significance of the educator and students' interaction as they engage in a creative process. Accompaniment which may be understood as being guided or mentored at some point throughout the process of learning is an important and critical factor. An educator's guidance is perceived by participants in the study as essential at the beginning of, and during the development of, any creative process, as well as during the assessment sessions. What seemed to underlie the importance of students' guidance by educators was the perception of mentoring as a factor that may minimise the effect of uncertainty, fear of error, assumption of risk and the comprehension and understanding of students involved in the artistic creative process.

\section{Time management}

Time preparing, delivering (performing, creating) and reflecting upon artistic and creative processes have been identified as an important factor that can be limiting. Some participants manifested the difficulty to manage the time for students to explore, to pose questions, to get lost and come to terms with what the preliminaries or tasks proposed were. Underlying this perception was the understanding of the creative process, as well as the teaching-learning process, as an experience that cannot be anticipated, neither accelerated. Occasionally, a difficulty for teachers to pause and step back from students' process-focused experience emerged too; this difficulty manifested in teachers finding it difficult to allow the students to experience the course of variations and intensities of the creative process: being in awe, bewilderment, feeling lost, becoming active, generating new insights, etc. At the same time, as expressed in the focus group, there seemed to be a general agreement on the current framework of shortening and intensification of academic courses as a factor of blocking creativity: for participants in the three focus groups, time becomes critical. For example since the Bologna agreement, HE Institutions within the framework, such as Vic University (Catalonia, Spain), now run programmes quarterly rather than annually; this was viewed as detrimental in terms of time afforded for the creative process to occur. In this context, time management should balance tensions between the time required for artistic exploration, production and assessment and time needed for contextualising, preparing, giving meaning, unifying concepts and final observing. While it's true that many students are engaged in creativity through artistic practice, it is also true that many others may experience feelings of confusion, bewilderment, even anxiety.

\section{Individual background}

The contextual and personal background seems to emerge as possible conditioning factors in some cases. Each student comes from different previous experiences, more so within the Spanish framework where there is no art specialist in Primary Education: diverse perceptions, experiences and expectations about what art education is, coexist within the culture of $\mathrm{HE}$. And simultaneously there is the necessity to become adjusted to the different learning styles and teaching philosophies. These different approaches to artmaking and creative thinking may emerge within the space of teaching-learning as barriers that inhibit the flow of actions and thought in creative processes. 
Potential solutions

Some experience-based ideas that may allow the removal or minimisation of some of the barriers emerged during the three focus groups. Many of these ideas have not been fully agreed upon or need some nuanced understanding. The concepts of accompaniment, time, blocking, risk, reflection and of course, creativity or assessment (Figure 1) were in the core of the focus groups as recurring elements. However, other concepts less cited, such as relationship, patience, and humour, have been identified too, as significant factors involved in the creative process within a pedagogical event. They suggest possible venues to minimise some of the barriers, as discussed in the following section.

\section{Conclusions}

Findings of this study are in accord with the existing literature, yet factors that may trigger individual reluctance or emotional blocking are widely differing. Fear is a significant individual blocking factor. This fear is perceived by teachers as fear of failing, of not having good grades, and foremost, the fear of uncertainty. In all cases, there is a resonance with inhibition/shyness factors described in the "Inventory of Barriers to Personal Creativity" (Alencar, 1999; Morais et al., 2014a, b). In the aim to remove or overcome that fear, the result of our analysis points to the importance of giving a safe space to our students. According to Jackson (2004a, b), it's important to provide safe spaces where they can try new things out and also, give students the confidence to take risks, or as artist William Kentridge summarises when referring to the art studio as a safe space for stupidity. Likewise, the findings suggest that this safe space is in correlation with the teacher's role throughout the creative process: the emerging theme of accompaniment or the perceived need for students to be accompanied and guided in this process.

What seemed to underlie the importance of students' guidance by educators was the perception of mentoring as a factor that may minimise the effect of uncertainty, fear of error, assumption of risk and the comprehension and understanding of students involved in the artistic creative process.

Allowing this feeling of freedom would promote self-esteem and self-confidence. Perhaps considering, tolerance for error would be an appropriate principle as part of an educators'

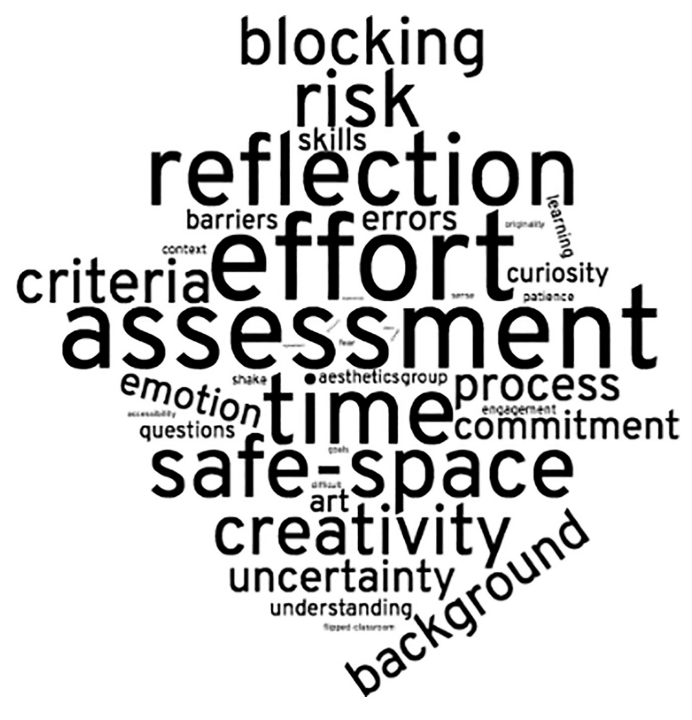

Figure 1. Graphic summary of concepts labelled and seized according to the frequency of their emergence 
JWAM

12,2

216

disposition. It is one of the seven principles of Universal Design (Connell et al., 1997), a theoretical framework that allows and guides the design of products and environments to be useable to the greatest extent possible by people of all ages and abilities/disabilities. Thus, from constructivist and other educational frameworks the importance of climate in the classroom for learning processes is reinforced (McGuire and Scott, 2006; Reyes et al., 2012)

Other related elements to the emotional and personal reluctance dimension are understanding or giving meaning and sense to the educational need for either an artistic or creativity-based educational process (and assessment). As argued by Jackson (2006a) this reluctance may be bounded too, to $\mathrm{HE}$ cultures and their difficulty to recognise creativity as an explicit learning objective and as part of the assessment criteria. Yet, this does not seem to be the climate within the context of the participants of this study and within the institution that they teach.

Additionally, the management of rhythms or tempi is perceived for participants as a critical factor for a successful arts-based learning activity or process. Otherwise, environmental pressure might appear. About creativity, focus group participants agreed that there was strong interdependency between time management and accompaniment. Aspects as exploration, fostering autonomy, understanding the educational meaning of the artistic assessment process are undoubtedly time dependent. According to Jackson (2006a, b), having sufficient time and space in the curriculum to allow students to develop their own creativity is one of the conditions that appear to facilitate students' creativity. Morais et al. (2014a) identified as main lack of time dimension factors: Personal time to explore, to put ideas on practice or develop them, evaluate them. As Blamires and Peterson (2014) recognise, the meaning of creativity is an important aspect that might be understood in terms of classroom practice especially in relation to the concept of assessment for learning. Our findings reinforce those personal time requirements but also recognise the need of time to: minimise effects of individual starting points, give meaning to the creative process, unifying criteria, allowing errors and tentatives or allowing the discovery. McWilliam (2007) states that: "there is risk in holding on and risk in letting go. And there is additional risk in insisting that we can and should know exactly when and how to count creativity as a singular graduate attribute" (p. 10). Indeed, time is fundamental in the creative process management in HE, especially with students not familiar with artistic creation. This time requirement factor undoubtedly needs further development in any future study.

An aspect that oftentimes emerged within the focus groups was the student's capacity to reflect upon their creative practice and performance, as well as about their learning. The capacity to reflect emerged at first as a desirable or required learning competence in HE students. It was proposed too as a means to assess their curiosity and autonomy, while involved in creative tasks. Students' capacity to pose or elaborate questions along their learning paths could additionally be a solution to creativity barriers: while it may help teachers to assess students' engagement, it may also provide indicators for teachers who want to accompany or guide the students throughout the creative process. And simultaneously, the creation of opportunities for questioning suggests the possibility of an individual transformation, and to an extent, a transformation of the meaning of creativity itself: breaking through conventions that present it as an individual and somewhat elevated attribute (Dellas and Gaier, 1970); breaking through the correlation of creativity with novelty and originality, and instead dislocating the focus from the outcome to the process, focusing on students' capacity to pose and elaborate questions.

A careful and respectful view from teachers seems to be important to promote creativity in HE. In conjunction with the error acceptance as a part of the learning process. We agree with Jackson $(2006 \mathrm{a}, \mathrm{b})$ that teachers who care about creativity can overcome these implied barriers. The present study cannot attempt to offer a complete detailed analysis of these general questions. 
Finally, some unexpected factors have emerged tangentially. While they probably cannot be considered as root factors, overall they seem to indicate that in the challenge of using artistic practices to promote creativity in HE, teachers need to develop personal qualities like patience and a sense of humour. Perhaps indicative that the themed four dimensions have implications for and beyond classroom educational settings, connecting once again with the point that arts education is seen as a cornerstone of socio-cultural practice beyond the classroom as Eisner (2012) states and is a point made in the earlier part of the paper and is furthermore a rationale showing why arts education matters to everyone out there in the workplace/social learning environment.

For example, accompaniment could be used to support creativity in the workplace, in a similar way that a coach, mentor or more knowledgeable other might provide scaffolding or question the learner of a new skill or knowledge base of a creative practice, in order that it is more experientially understood.

Perhaps in a complimentary manner, accompaniment in the workplace is as much about ensuring that a creative practice is confidently engaged with as it is experientially understood. The role is in many cases then, about challenging and emotionally supporting another when the risk of error seems daunting.

We recognise the contextual scope of this case study as limited. To develop a broader scope, factors would require extending the investigation to new settings, different universities, different countries and different cultural frameworks. This would certainly have the capacity to broaden and deepen the initial findings. Nonetheless, it seems that creativity is a desirable outcome and skill in HE. However, it is dependent on a plethora of external, personal, background or emotional factors, any of which may generate some reluctance or barriers to the process. This first phase study points out that creativity could be a limiting goal for some people, possibly even beyond HE contexts.

The results of this study indicate that when creative practices, arts or artistic formats are used as a learning or assessment method it is important to take care to avoid or minimise these potential barriers and difficulties.

\section{References}

Alencar, E.M. (1999), "Barreiras à criatividade pessoal: Desenvolvimento de um instrumento de medida [Obstacles to personal creativity: the development of a measurement instrument]", Psicologia Escolar e Educacional, Vol. 3, pp. 123-132.

Alencar, E.M. (2001), "Obstacles to personal creativity among university students", Gifted Education International, Vol. 15 No. 2, pp. 133-140.

Alencar, E.M., Fleith, D.D.S. and Martinez, A.M. (2003), "Obstacles to personal creativity between Brazilian and Mexican university students: a comparative study", Journal of Creative Behavior, Vol. 37 No. 3, pp. 179-92.

An, D. and Youn, N. (2018), "The inspirational power of arts on creativity", Journal of Business Research, Vol. 85, pp. 467-475.

Atkinson, D. (2016), "Without criteria: art and learning and the adventure of pedagogy", The International Journal of Art and Design, Vol. 36 No. 2, pp. 141-152, doi: 10.1111/jade.12089.

Boden, M.A. (2005), "What is creativity?", in Mithen, S. (Ed.), Creativity in Human Evolution and Prehistory, Routledge, London, (1999). doi: 10.4324/9780203978627.

Blamires, M. and Peterson, A. (2014), "Can creativity be assessed? towards an evidence-informed framework for assessing and planning progress in creativity", Cambridge Journal of Education, Vol. 44 No. 2, pp. 147-162.

Braun, V. and Clarke, V. (2006), "Using thematic analysis in psychology", Qualitative Research in Psychology, Vol. 3 No. 2, pp. 77-101. 
JWAM

12,2

Bronner, S.J. (2015), "Toward the formulation of a folkloristic theory of mind: the role of psychoanalysis and symbolist approaches to tradition”, Milli Folklor, Vol. 27 No. 108, pp. 18-30.

Connell, B., Jones, M., Mace, R., Mueller, J., Mullick, A., Ostroff, E., Sanford, J., Steinfeld, E., Story, M. and Vanderheiden, G. (1997), The Principles of Universal Design, Center for Universal Design, North Carolina State University, Raleigh, NC.

Craft, A. (2001), Analysis of Research and Literature on Creativity in Education, available at: http:// www.creativetallis.com/uploads/2/2/8/7/2287089/creativity_in_education_report.pdf.

Craft, A. (2005), Creativity in Schools: Tensions and Dilemmas, Routledge, London.

Creswell, J.W. (2007), Qualitative Enquiry and Research Design: Choosing Among Five Approaches, Sage Publications, Thousand Oaks, CA.

Cropley, A. and Cropley, D. (2008), "Resolving the paradoxes of creativity: an extended phase model", Cambridge Journal of Education, Vol. 38 No. 3, pp. 355-373, doi: 10.1080/03057640802286871.

Csikszentmihalyi, M. (2009), Flow: The Psychology of Optimal Experience, Harper and Row, New York, NY.

Dellas, M. and Gaier, E.L. (1970), "Identification of creativity: the individual", Psychological Bulletin, Vol. 73 No. 1, pp. 55-73.

Dewey, J. (1934/2005), Art as Experience, Penguin Group, New York, NY.

Eisner, E. (2012), The Arts and the Creation of Mind, Yale University Press, New Haven.

Hilala, H.M.H., Husinb, W.N.I.W. and Zayeda, T.M. (2013), "Barriers to creativity among students of selected universities in Malaysia", International Journal of Applied, Vol. 3 No. 6.

Huerta, R. (2019), Arte para primaria, Editorial UOC, Barcelona.

Jackson, N. (2006a), "Creativity in higher education, SCEPTrE Scholarly Paper, Vol. 3, pp. 1-25.

Jackson, N. (2006b), “Creativity in higher education: what's the problem?”, Higher Education, Vol. 7, pp. 1-11.

Jahnke, I., Haertel, T. and Wildt, J. (2017), “Teachers' conceptions of student creativity in higher education", Innovations in Education and Teaching International, Vol. 54 No. 1, pp. 87-95.

Kaufman, J. (2016), "The creative construct", RSA: 21st Century Enlightenment No. 1, pp. 24-27.

Kaufman, J.C. and Beghetto, R.A. (2009), "Beyond big and little: the four C model of creativity", Review of General Psychology, Vol. 13 No. 1, pp. 1-12.

Kazerounian, K. and Foley, S. (2007), "Barriers to creativity in engineering education: a study of instructors and students perceptions", Journal of Mechanical Design, Vol. 129 No. 7, pp. $761-768,1990$.

Konstantinidou, E., Zisi, V., Katsarou, D. and Michalopoulou, M. (2015), "Barriers and inhibitors of creativity in physical education", European Psychomotricity Journal, Vol. 7 No. 1, pp. 17-31.

Kleiman, P. (2008), "Towards transformation: conceptions of creativity in higher education", Innovations in Education and Teaching International, Vol. 45 No. 3, pp. 209-217.

Krueger, R.A. (2014), Focus Groups: A Practical Guide for Applied Research, Sage publications, Thousand Oaks, CA.

MacDonald, R., Byrne, C. and Carlton, L. (2006), "Creativity and flow in musical composition: an empirical investigation", Psychology of Music, Vol. 34 No. 3, pp. 292-306.

McGoldrick, C. (2002), Creativity and Curriculum Design: What Academics Think. Commissioned Imaginative Curriculum Research Study, LTSN Generic Centre, available at: http://citeseerx.ist.psu. edu/viewdoc/download?doi=10.1.1.454.5537\&rep=rep1\&type=pdf (accessed 6 March 2020).

McGuire, J.M. and Scott, S.S. (2006), "Universal design for instruction: extending the universal design paradigm to college instruction", Journal of Postsecondary Education and Disability, Vol. 19 No. 2, pp. 124-134. 
McWilliam, E.L. (2007), "Is creativity teachable? conceptualising the creativity/pedagogy relationship in higher education", available at: http://eprints.qut.edu.au/15508/1/15508.pdf (accessed 14 January 2020).

Morais, M.D.F., Almeida, L.S., Azevedo, I., Alencar, E. and Fleith, D. (2014a), "Inventory of barriers to personal creativity: a validation study involving university students", European Proceedings of Social and Behavioural Sciences, Vol. 1, pp. 135-145.

Morais, M.D.F., Almeida, L.S., Azevedo, I., Alencar, E. and Fleith, D. (2014b), "Perceptions of barriers to personal creativity: validation of an Inventory involving High Education students", European Journal of Social and Behavioural Sciences, Vol. 3 No. 10, pp. 1478-1495, doi: 10.15405/ejsbs.133.

Oliver, M. (2002), "Creativity and the curriculum design process: a case study", Higher Education Academy, available at: http://www.heacademy.ac.uk/resources.asp (accessed 28 February 2020).

Onwuegbuzie, A.J., Dickinson, W.B., Leech, N.L. and Zoran, A.G. (2009), "A qualitative framework for collecting and analyzing data in focus group research", International Journal of Qualitative Methods, Vol. 8 No. 3, pp. 1-21.

Poole, S. (2017), Cornucopia: Innovation. (3), FECS, Chester, 2516-2667.

Rabiee, F. (2004), "Focus-group interview and data analysis", Proceedings of the Nutrition Society, Vol. 63 No. 4, pp. $655-660$.

Reyes, M.R., Brackett, M.A., Rivers, S.E., White, M. and Salovey, P. (2012), "Classroom emotional climate, student engagement, and academic achievement", Journal of Educational Psychology, Vol. 104 No. 3, p. 700.

Robinson, K. and Craft, A. (1999), All Our Futures: Culture, Creativity and Education, National Advisory Committee on Creative and Cultural Education (NACCCE), London.

Runco, M.A. and Jaeger, G.J. (2012), "The standard definition of creativity", Creativity Research Journal, Vol. 24 No. 1, pp. 92-96.

Silver, P., Bourke, A. and Strehorn, K.C. (1998), "Universal Instructional Design in higher education: an approach for inclusion”, Equity and Excellence, Vol. 31 No. 2, pp. 47-51.

Soja, E. (1996), Thirdspace: Journeys to Los Angeles and Other Real-And-Imagined Places, Blackwell Publishers, MA.

Stake, Robert E. (1995), The Art of Case Study Research, SAGE Publications, London.

Torrance, E.P. (1966), Torrance Tests of Creativity, Personnel Press, Princeton.

\section{Further reading}

Adams, J. and Owens, A. (2015), Creativity and Democracy in Education: Practices and Politics of Learning through the Arts, Routledge, Abingdon and New York, NY.

Alencar, E.M. and Fleith, D.D.S. (2004), "Inventário de práticas docentes que favorecem a criatividade no ensino superior", Psicologia: Reflexão e Crítica, Vol. 17 No. 1, pp. 105-110.

Kidd, P.S. and Parshall, M.B. (2000), "Getting the focus and the group: enhancing analytical rigor in focus group research", Qualitative Health Research, Vol. 10 No. 3, pp. 293-308.

McWilliam, E., Hearn, G. and Haseman, B. (2008), "Transdisciplinarity for creative futures: what barriers and opportunities?", Innovations in Education and Teaching International, Vol. 45 No. 3, pp. 247-253.

Schmid, T. (2004), "Meanings of creativity within occupational therapy practice", Australian Occupational Therapy Journal, Vol. 51 No. 2, pp. 80-88.

Scott, D., Nottingham, P. and Wall, T., Call for Papers for a Special Issue on: "Creativity in Work-Applied Management".

Story, M.F., Mueller, J.L. and Mace, R.L. (1998), The Universal Design File: Designing for People of All Ages and Abilities, North Carolina State University, Raleigh, NC, available at: http://www. design.ncsu.edu/cud/pubs_p/pud.htm (accessed 20 February 2020). 
JWAM

12,2

\begin{abstract}
About the authors
Lluís Solé is a musician and researcher. Is also Professor of Music Pedagogy at Universitat de VicUniversitat Central de Catalunya in Spain. He was initially educated as a Biologist but also as a piano, recorder, harpsichord, cornett and bansuri player. He has worked as a music soloist and as a teacher in secondary education. Also is founder and conductor of the UVic's Inclusive Orchestra, an access and equity project on music practice based in the application of Universal Design Principles to orchestras. His interests are focused on accessibility in instrumental music-making and participation in music regardless of individual musical skills (abilities). He is also interested in the Arts-Based processes through music.

Laia Sole-Coromina is a visual artist art educator and current Professor of art education at Universitat de Vic (Spain). Her research interests include social space, art practices as sites of learning, and arts-based research. She holds a Doctorate in Education by Teachers College, Columbia University, with a dissertation on art, play and social space. As an artist, she is interested in activating new ideas about spatiality. Her artwork has been exhibited in group shows at The Drawing Center (New York), Cuchifritos Gallery (New York) or Fabra i Coats (Barcelona), among others.

Simon Ellis Poole is the Senior Lead in Cultural Education and Research at Storyhouse, Chester's award-winning theatre; Programme Leader for the Masters in Creative Practice in Education at the University of Chester; Researcher at the Centre for Research into Education, Creativity and Arts through Practice (RECAP); and Researcher with the International Thriving at Work Research Group. He has held positions outside of the university too, such as the Director of Research for 'Lapidus International' and Vice-Chair of the Local Cultural Education Partnership. He is also Managing Director of Soil Records; Singer with 'the loose kites' and is a published poet and author. Simon Ellis Poole is the corresponding author and can be contacted at: simon.poole@chester.ac.uk
\end{abstract}

For instructions on how to order reprints of this article, please visit our website:

www.emeraldgrouppublishing.com/licensing/reprints.htm

Or contact us for further details: permissions@emeraldinsight.com 